and the Russian-born Selman Waksman of Rutgers University, whose team in 1943 isolated streptomycin, which proved a potent antibiotic treatment against tuberculosis. Each of these books combines meticulous scholarship with compassion and imagination. This distinguished collection of medical history has now been joined by Dormandy's The White Death.

Dormandy is a consultant pathologist who has for many years collected references to the history of tuberculosis, and the impact of the disease on society, the arts and literature. His approach is erudite, witty, humane and authoritative. He has some masterful character portraits of physicians and scientific researchers, and has studded his text with arresting maxims: he writes of Koch that "his postulates established the science of medicine as the equal of the art of medicine". There are many pleasing idiosyncrasies and digressive footnotes; but best of all Dormandy provides a truly international survey which repeatedly cites examples that will be unfamiliar to English-language speakers. Although there are some amateurish repetitions and evidence of obtrusively inadequate proofreading, The
White Death can be enthusiastically recommended to all those interested either professionally in tuberculosis or recreationally in the cultural history of medicine.

Richard Davenport-Hines is at 51 Elsham Road, London W14 8HD, UK.

\section{... nor any drop to drink}

\section{Fresh Water}

by E. C. Pielou

University of Chicago Press: 1998. 274 pp.

$\$ 24.00, £ 19.25$

The World's Water 1998- 1999: The Biennial Report on Freshw ater

\section{Resources}

by Peter H. Gleick

Island: 1998. 306 pp. \$29.95, £24.95 (pbk)

Daniel Hillel

In many ways, E. C. Pielou's comprehensive and comprehensible book describing the cycle of water in the terrestrial environment (especially as it is influenced by human inter- vention) is reminiscent of Luna Leopold's classic Water: A Primer, published some 25 years ago. Fresh Water is evidently intended to teach lay readers about the crucial issues posed by the dwindling supplies and deteriorating quality of fresh water available for human use. Her writing is didactic and definitive, in places even charming, and is buttressed by clear illustrations, avoiding rigorous mathematical formulations. Especially enlightening are the explanations of such complex phenomena as hydraulic jumps, the transition from laminar to turbulent flow, water movement in aquifers, the nature of karst and the tendency of rivers to meander.

Considering the enormous breadth and complexity of the topic, however, it is not surprising to discover a few flaws. Simplistic statements occur here and there. One is the characterization of clay as 'rock flour', when in fact clay generally consists of altered ('secondary') minerals (for example, aluminosilicates) with very different physico-chemical attributes from those of the original ('primary') minerals of the parent rocks.

\title{
In retrospect chosen by Anton Zeilinger
}

\section{Albert Einstein: \\ Philosopher- Scientist \\ edited by Paul Arthur Schilpp}

"Here I sit in order to write, at the age of 67, something like my own obituary." With these words Albert Einstein starts his only existing autobiography, his "Autobiographical Notes". Around the middle of the twentieth century the philosopher Paul A. Schilpp published a series of books under the heading "The Library of Living Philosophers"; each contains essays written by one leading philosopher — such as Karl Popper, Bertrand Russell or Jean-Paul Sartre — and by some of his peers.

Einstein's “Autobiographical Notes", written in German and translated into English by Schilpp, with both versions in the book, are among the most outstanding intellectual reflections ever written. He tells us that "Even when I was a fairly precocious young man the nothingness of the hopes and strivings which chase most men restlessly through life came to my consciousness with considerable vitality". But he then goes on to ask the humble question, "What, precisely, is 'thinking'?". He agrees with the philosopher David Hume that certain concepts, like causality, cannot be deduced, but he disagrees that the specific concepts chosen by Immanuel Kant are indispensable, preferring to call them "freely chosen conventions".

Einstein discusses many issues. He complains about university education. "It is, in fact, nothing short of a miracle that the modern methods of instruction have not yet entirely strangled the holy curiosity of inquiry." One can only regret that most countries' education systems have taken the road towards less rather than more freedom as demanded by Einstein.

Later on, Einstein gives us many details of how he was led to his theories of relativity and their fundamental ideas, mentioning most prominently the influence of Ernst Mach. It is very moving when he tells us that by the age of 16 he had realized that if one could proceed alongside a beam of light with the same speed, one would see impossible configurations of electric fields.

Parts of the book have already become classics, for example where Einstein discusses his views of quantum mechanics and where Niels Bohr documents his "Discussions with Einstein about epistemological problems in atomic physics". The latter is one of the most momentous debates that ever took place. Einstein, while he admits quantum theory is "the most successful physical theory of our period", nevertheless concludes that it "offers no useful point of departure for future development". He reaches that conclusion by analysing what he believes physics should be about. For him, "Physics is an attempt conceptually to grasp reality as it is thought independently of its being observed. In this sense one speaks of 'physical reality."

Einstein carefully analyses the situation of two quantum-mechanically correlated, so-called entangled, systems. He points out that observation of one system immediately changes the quantum state of the other regardless of how far apart they are. Yet, as Einstein says, "the real situation" of the second system "must be independent of what happens" to the first

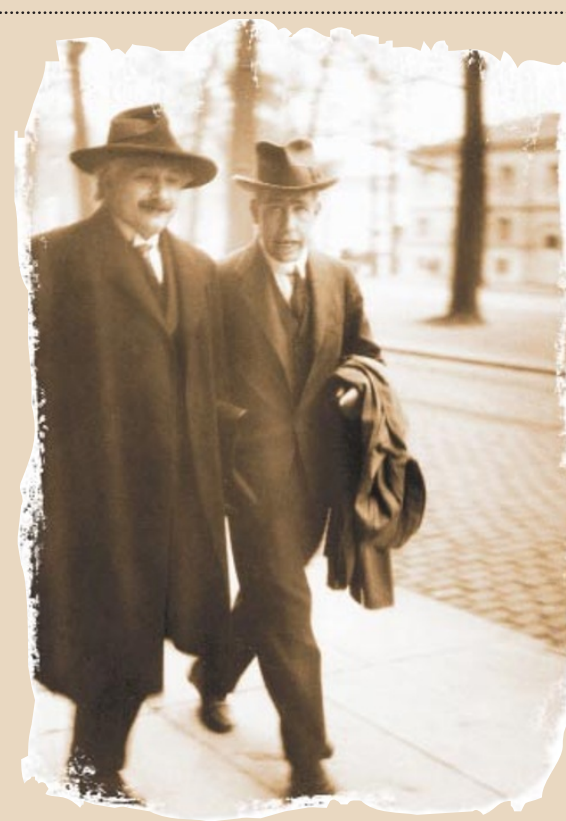

In discussions: Einstein and Bohr in 1930.

system. He decides that "One can escape this conclusion only by either assuming that measurement of one system (telepathically) changes the real situation of the other or by denying independent real situations to such separated systems". Both alternatives appear to him entirely unacceptable.

Bohr, in his essay, shows beautiful drawings of the gedanken experimental set-ups, like the famous two-slit and photon-in-a-box arrangements, suggested by Einstein in order to show that there is something wrong with 
Similarly misleading are the anachronistic classification of soil moisture into distinct categories and the definitions of such concepts as 'field capacity' and 'wilting points' (the latter erroneously equated with hygroscopic moisture). In recent decades, these static concepts have been superseded by an understanding of the interactive dynamics between water and the soil-plant-atmosphere continuum.

The author's strong opinions occasionally interfere with the objective treatment of the subject; an example is her blanket condemnation of dam projects. And any book necessarily reflects its author's experience and perception. As Pielou is Canadian, it is natural that her book should include an extensive (and interesting) treatment of freezing and thawing phenomena. On the other hand, the book does not give a proportionate treatment of water relations in the semi-arid, arid and extremely arid (desert) regions that cover so much of our globe and in which so many nations struggle to subsist. Notably absent also is any description of tropical regions (such as the tropical rainforests), where the land,

\section{A planet's life blood}

Images of water in all its forms can be found in Water: Worlds Between Heaven and Earth (Stewart, Tabori \& Chang, \$50, $\mathfrak{E 3 5}$ ), with photographs by Art Wolfe and text by Michelle A. Gilders and Claus Biegert. Publication of the book is scheduled for 31 May.

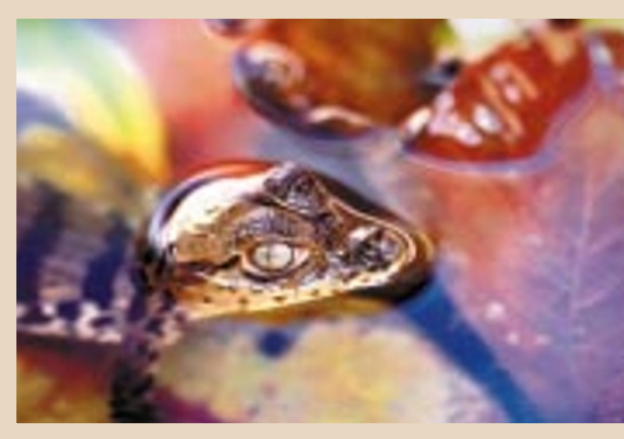

water and biotic resources are particularly vulnerable to destruction.

Such criticisms notwithstanding, I found Pielou's book a welcome addition to the genre of literature designed to bridge the gap

continuum. Georges Lemaitre's discussion of the cosmological constant is an example of a topic that has recently come into focus again because of observed hints of an anomalous expansion of the Universe. Lemaitre wisely notes that "The history of science provides many instances of discoveries which have been made for reasons which are no longer considered satisfactory".

In that spirit, we note that quantum entanglement is one such case. Einstein clearly foresaw its enormous philosophical consequences, which motivated him to introduce it in his critique of quantum physics. While that critique can hardly be upheld today, entanglement became the central concept in the newly emerging field of quantum information, which includes such eye-catching topics as teleportation and quantum computation. It is tantalizing to contemplate Einstein's and Bohr's reactions to the enormous experimental progress made in recent years. Realization of many of the old gedanken experiments and their refinements have given rise to a generation of physicists to whom experiments with individual quanta are an everyday experience in the laboratory, and who have thus obtained a natural, intuitive understandiung of quantum phenomena.

Bohr, in his essay, mentions the "benefit from the inspiration which we all derive from every contact with Einstein". This, I promise, will be true for every patient reader of the book, who has a wonderful opportunity to encounter one of the greatest minds of all time.

Anton Zeilinger is at the Institute of Experimental Physics, Vienna University, Boltzmanngasse 5, 1090 Vienna, Austria.

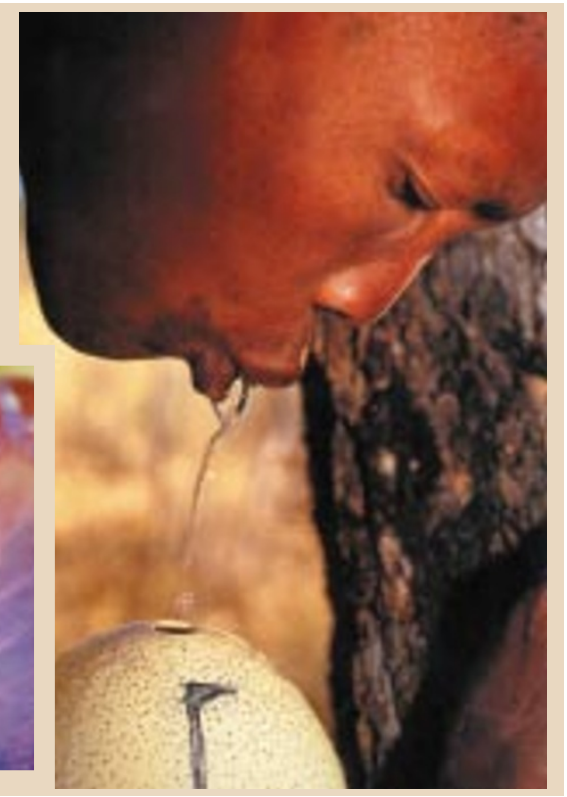

between scientists, with their specialized jargon and occasionally obtuse theories, and the intelligent and concerned lay public. In a democratic society, communicating sound science to the public is essential if we are to enlist wide support for the actions necessary to resolve the environmental issues involving water that confront nations and the international community with increasing severity and urgency.

The World's Water by Peter H. Gleick apparently has the same aim as Pielou's book, though it differs greatly in structure and content. Unlike Fresh Water, and despite its seemingly inclusive title, it is not in itself a complete book. Rather, it is a somewhat disjointed collection of disparate items, including data gleaned from UN agencies and the World Bank, reviews of recent developments on water projects and their management, conjectured prospects for the future, and editorial opinions of the various topics covered.

Given Gleick's earlier seminal contribution to the field (Water in Crisis, Oxford University Press; 1993), we might have expected fuller coverage. However, the selection of topics and items is somewhat arbitrary. The exposition attempts to be authoritative, but is rather journalistic in tone and style. The whole appears to be an effort to emulate the annual WorldWatch "State of the World" publications addressed to a more specific topic.

What this volume does most laudably is argue the case for a shift of emphasis from the supply-side of water management to the demand-side, stressing the need and potential for improved efficiency of water use through conservation, recycling and environmental sustainability. Another important issue mentioned, if not fully resolved, is the treatment of water as an economic commodity. Pricing water may very well promote efficient use but might 
not ensure that long-term environmental considerations are properly taken into account.

In a section entitled "A vision for 2050", Gleick presents an optimistic future, presumably conditional on the timely adoption of appropriate policies. This is a useful exercise, inasmuch as it offers hope rather than gloom. It would have been even more useful, however, had the author mapped out alternative scenarios (at least semi-quantitatively), comparing and contrasting the probable outcomes of specified circumstances (for example, rising or falling energy costs, or climatic changes resulting in increased or reduced availability of water) and policies (pricing of water and other incentives to promote water conservation). Gleick makes much of the concept of basic needs for water, but does not discuss how such needs are conditioned by climate, type of economy or mode of subsistence.

Perhaps the most useful section of the volume is the Data Section, where updated information is given in tabular form. However, in presenting the total renewable freshwater supply for each country, the data are seriously flawed in failing to subtract the volume of flow discharged to downstream countries. As a result, the same volumes of water are counted several times over (as in the case of Ethiopia, Sudan and Egypt, for example). As the data are taken from various sources, critical evaluations of their reliability would also have been helpful.

As this is only the first of what is evidently intended to constitute a series of books to be published every two years, we can only hope that subsequent volumes will provide a more complete coverage of the topics

\section{New in paperback}

\author{
Hunting Dow $\mathbf{n}$ the Universe: The \\ Missing Mass, Primordial Black Holes \\ and Other Dark Matters \\ by Michael Hawkins with Celia Fitzgerald \\ Perseus, $\$ 13$ \\ "...his hypothesis is very likely to be \\ disproved to the satisfaction of any \\ sapient individual. If, on the other hand, \\ his theory is observationally confirmed, \\ then he will without doubt be acclaimed \\ by the establishment, and I will eat this \\ review." William Press, Nature 388, 138 \\ (1997).
}
A bout Face
by Jonathan Cole
MIT Press, \$16.81, £15.85
"Cole believes that facial expressions are the main way to communicate emotion, and to prove his point he has had the ingenious idea of examining the deficits of those who either

and issues that would be properly included under the encompassing title The World's Water.

Daniel Hillel is Professor Emeritus of Environmental Physics and Hydrology,

University of Massachusetts, Amherst,

Massachusetts 01003, USA.

\section{Sounding out two centuries}

\section{Sounds of Our Times: Tw o Hundred Years of Ac oustics \\ by Robert T. Beyer}

Springer: 1999. 444 pp. $\$ 49.95$, 237.50

\section{J.Woodhouse}

The science of sound and vibration has come down in the world during the twentieth century. It occupied a position of pre-eminence in antiquity, with the Pythagorean views of universal harmony and the 'music of the spheres'.

By the nineteenth century it was still in the mainstream of rapidly developing physical science, and many famous names made contributions: scientists like Hermann von Helmholtz, Lord Rayleigh, Gustav Kirchhoff and Joseph Henry, and inventors like Alexander Graham Bell and Thomas Edison. In the twentieth century the subject has lacked the glamour of quantum mechanics, astrophysics or molecular biology, but nevertheless research has continued with accelerating pace.

Robert Beyer's engagingly written history of the subject since 1800 tells the whole story, and may help restore some sparkle to a Cinderella subject. It is liberally supplied

cannot interpret the expressions of others ... or cannot display such expressions themselves." Stuart Sutherland, Nature 390, 458 (1997).

The Universe Below : Dis c overing the Secrets of the DeepSea

by William J. Broad, illustrations by Dimitry Schidlovsky

Simon \& Schuster, \$15, £9.99

The Thermal Warriors: Strategies of Insect S urvival by Bernd Heinrich

Harvard University Press, \$17.95

Visions: How Science w ill Revolutionize the 2 lst Century and Beyond

by Michio Kaku

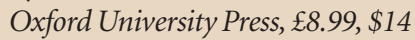

with period illustrations and anecdotes, while maintaining a high standard of technical accuracy and completeness. Among the many gems is the first experimental verification of the formula for the Doppler effect, when the experimental apparatus consisted of a steam locomotive, several trumpeters and some musically trained observers. Beyer also describes the long story of ways to visualize and measure waveforms of sound and vibration - from Helmholtz resonators, tuning-forks and rotating mirrors through the early developments in electromagnetic devices, up to modern electronic and computer-based methods.

During this century the scope of the subject has expanded enormously, with such topics as underwater acoustics, architectural acoustics and ultrasonics. All are covered in Beyer's systematic account, which draws especially on the author's long association with the Acoustical Society of America whose journal and regular conferences provide invaluable raw material, while the society itself is included as part of the history of the subject.

The book comes right up to date with an inevitably brief overview of recent developments and trends across the whole field, from structural vibration to the physiology of hearing. The result is of interest to any scientific reader. Those working in the subject will naturally turn first to the reference list to see if they are mentioned. I wasn't, but I was quite impressed at the choice of modern developments in the areas with which I am familiar.

It would be unrealistic to expect such a general book to give a definitive review of every speciality, but Beyer has made a very creditable stab. This book combines good science with being a good read. It should make its way into many libraries, and onto many bedside tables.

J. Woodhouse is in the Department of Engineering, University of Cambridge, Cambridge CB2 1PZ, UK. 